\title{
Erratum to: The Architecture of Scientific Software
}

\author{
Ronald F. Boisvert ${ }^{1}$ and Ping Tak Peter Tang ${ }^{2}$ \\ 1 National Institute of Standards and Technology, USA \\ ${ }^{2}$ Intel Corporation, USA
}

\section{Erratum to: \\ R.F. Boisvert and P.T.P. Tang (Eds.) \\ The Architecture of Scientific Software DOI: $10.1007 / 978-0-387-35407-1$}

The book was inadvertently published with an incorrect name of the copyright holder. The name of the copyright holder for this book is: (c) IFIP International Federation for Information Processing. The book has been updated with the changes.

The updated original online version for this book can be found at DOI: $10.1007 / 978-0-387-35407-1$ 